\title{
MPPT Technique Based on Current and Temperature Measurements
}

\author{
Eduardo Moreira Vicente, Robson Luiz Moreno, and Enio Roberto Ribeiro \\ Departamento de Engenharia Elétrica, Universidade Federal de Itajubá (UNIFEI), Avenida BPS 1303, Bairro Pinheirinho, \\ 37500-903 Itajubá, MG, Brazil
}

Correspondence should be addressed to Eduardo Moreira Vicente; eduardomoreira@unifei.edu.br

Received 28 November 2014; Accepted 11 February 2015

Academic Editor: Euzeli dos Santos Jr.

Copyright (C) 2015 Eduardo Moreira Vicente et al. This is an open access article distributed under the Creative Commons Attribution License, which permits unrestricted use, distribution, and reproduction in any medium, provided the original work is properly cited.

\begin{abstract}
This paper presents a new maximum power point tracking (MPPT) method based on the measurement of temperature and shortcircuit current, in a simple and efficient approach. These measurements, which can precisely define the maximum power point (MPP), have not been used together in other existing techniques. The temperature is measured with a low cost sensor and the solar irradiance is estimated through the relationship of the measured short-circuit current and its reference. Fast tracking speed and stable steady-state operation are advantages of this technique, which presents higher performance when compared to other well-known techniques.
\end{abstract}

\section{Introduction}

The use of renewable energy sources is a trend nowadays. The main renewable energy sources are wind and solar sources. The first depends on the movement of wind turbines, which limits its application to specific geographical areas, where the wind is constant [1]. The solar energy source depends mainly on the sunlight, which is abundant on Earth and provides about $63 \mathrm{TW}$ of power, daily [2].

Photovoltaic systems are an interesting alternative energy source. However, the barriers to its popularization are the cost of installation [3] and low efficiency of photovoltaic conversion, which is about $13 \%$ to $18 \%$ on average $[3,4]$. Due to its low performance, it is essential to extract all available PV module energy.

Modeling of a given PV module involves the analysis of its current versus voltage curve. This characteristic is nonlinear, and the maximum power point (MPP) changes with both solar irradiance and temperature.

Within this context, finding a proper MPP is often a difficult task that can be performed with maximum power point tracking (MPPT) systems.

MPPT systems modify the current and voltage of the PV module, causing it to operate at its MPP. At this point, the product of current and voltage of the PV module is maximum, as illustrated in Figure 1.

Any different point in these curves will cause the module to operate below its maximum power. To ensure that the MPP is maintained in any irradiance and temperature condition, MPPT techniques are used to define the operating point of the PV module.

\section{MPPT Techniques}

There are several techniques to achieve the MPP, which differ in some aspects, such as online or offline methods, search techniques, artificial intelligence-based methods, and modelbased or model-free methods [5-11].

Online methods need continuous sampling of system variables, to update the PV module measurements and, therefore, the MPP. Offline techniques are simpler and the operating points are predefined for a specific situation, without system data update [8].

Search techniques use system disturbances to find the maximum power point. The power output, resultant from this disturbance, is the parameter to define the MPP [12]. 


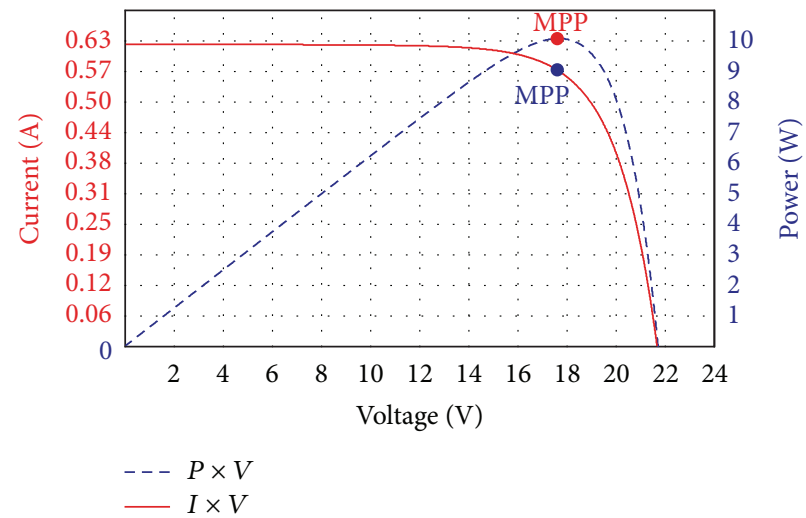

FIgURE 1: Maximum power point in $I \times V$ and $P \times V$ curves.

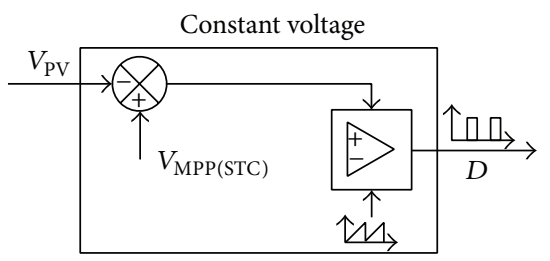

(a)

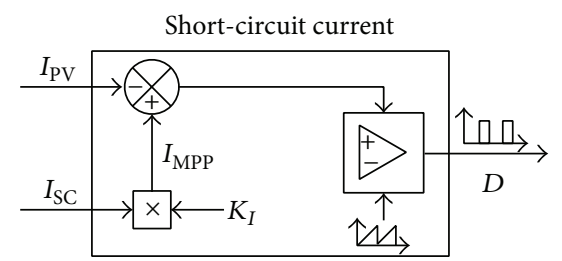

(d)

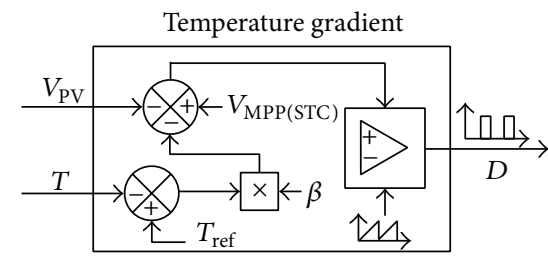

(b)

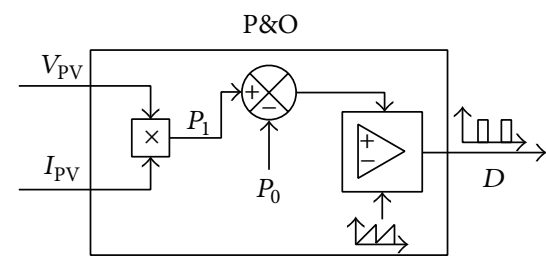

(e)

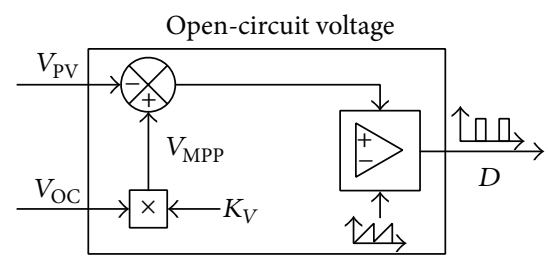

(c)

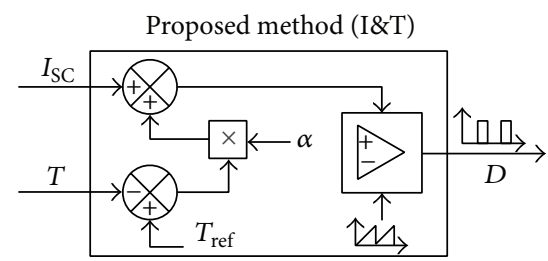

(f)

FIGURE 2: Block diagram representation of MPPT methods: (a) constant voltage; (b) temperature gradient; (c) open-circuit voltage; (d) shortcircuit current; (e) P\&O; (f) I\&T.

Artificial intelligence-based methods use complex mathematical models and systems that require high computational efforts, to obtain an accurate and reliable model of the $I \times V$ curve. The system modeling allows the determination of the MPP with high accuracy level [7].

The model-based methods require system parameters, as the internal resistances and the maximum values of current and voltage in the Standard Test Condition (STC), to track the MPP. On the other hand, model-free systems establish the MPP with measurements of the PV module output [11].

Figure 2 shows the block diagram representations of six distinct MPPT methods. The first five MPPT methods are frequently reported in the literature [12-20] and the last one is the proposed method. In the constant voltage method $[6,15]$, the voltage at the MPP is established to the STC $\left(V_{\mathrm{MPP}(\mathrm{STC})}\right)$ and the voltage across the $\mathrm{PV}$ module $\left(V_{\mathrm{PV}}\right)$ is compared to this value, through

$$
V_{\mathrm{PV}}=V_{\mathrm{MPP}(\mathrm{STC})} \text {. }
$$

The duty cycle output $(D)$ is the result of the voltage error $\left(V_{\text {error }}=V_{\mathrm{MPP}(\mathrm{STC})}-V_{\mathrm{PV}}\right)$ and the reference signal (saw-tooth wave) comparison.
The temperature gradient technique $[16,17]$ uses the PV module temperature ( $T$ ) to modify $V_{\mathrm{MPP}(\mathrm{STC})}$, according to the voltage/temperature coefficient $(\beta)$, as seen in (2). The $\beta$ coefficient varies according to the type of module and its manufacturing process [12]:

$$
V_{\mathrm{PV}}=V_{\mathrm{MPP}(\mathrm{STC})}+\beta\left(T_{\text {ref }}-T\right) .
$$

Another widespread method is the open-circuit voltage $[14,18]$. This method uses the open-circuit voltage $\left(V_{\mathrm{OC}}\right)$ to estimate the MPP by means of a $K_{V}$ constant (between 0.7 and 0.8), which is related to the $V_{\mathrm{MPP}}$. This can be observed in

$$
V_{\mathrm{PV}}=K_{V} \cdot V_{\mathrm{OC}} \text {. }
$$

A similar technique is the short-circuit current $[19,20]$ where such parameter $\left(I_{\mathrm{SC}}\right)$ is compared with the output current $\left(I_{\mathrm{PV}}\right)$ through a constant $K_{I}(0.7$ to 0.95$)$, causing it to converge to the MPP. This relationship is presented in

$$
I_{\mathrm{PV}}=K_{I} \cdot I_{\mathrm{SC}} .
$$

The perturb and observe $(\mathrm{P} \& \mathrm{O})$ is another method widely used in commercial systems $[12,13]$. It operates by periodically changing the duty cycle $(D)$ of the dc-dc converter, 


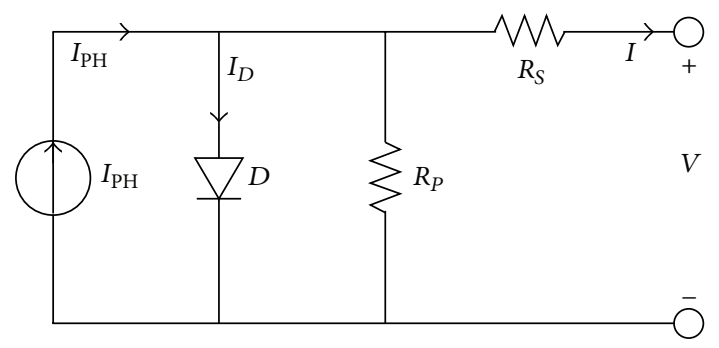

FIgURE 3: Equivalent circuit of the PV module.

comparing the previous $\left(P_{0}\right)$ and present $\left(P_{1}\right)$ output power, indicating whether $D$ should increase or decrease to reach the MPP, according to

$$
\begin{gathered}
P_{1}>P_{0}-\text { same direction } \\
P_{1}<P_{0}-\text { opposite direction. }
\end{gathered}
$$

If a certain perturbation causes an increase (or decrease) in power output, the following perturbation is made in the same (or opposite) direction. In this manner, the $\mathrm{P} \& \mathrm{O}$ continuously seeks the MPP [12].

This paper proposes the I\&T method, a new technique of MPPT. It uses two variables, the short-circuit current and temperature, which have not been used at the same time in other existing techniques. These variables are directly related to the influence of the irradiance and temperature on the PV module characteristics. The irradiance measurement is an important task and it is accomplished with a pyranometer sensor [21]. However, its cost is almost a hundred times greater than a voltage/current sensor. To overcome this drawback, in the I\&T method, the irradiance is evaluated through the relation of the measured short-circuit current and its reference at STC. This method uses low cost sensors to measure temperature and current, which accurately define the MPP.

\section{PV Module}

The operating principle of the silicon PV cell is the conversion of energy from the sun, of a specific wavelength (from $300 \mathrm{~nm}$ to $1100 \mathrm{~nm}$ ), into current [22]. The PV module is made of light sensitive semiconductor, which produces energy from solar radiation [4].

The circuit model of the PV module is shown in Figure 3. There are other models in the literature; however, the one used in this paper is simple and has satisfactory performance [11].

The incidence of light on the cell produces charge carriers that originate the photogenerated current $I_{\mathrm{ph}} \cdot I_{D}$ is the reverse saturation current of the PN junction. The series $\left(R_{S}\right)$ and shunt $\left(R_{P}\right)$ resistances represent the sum of several structural resistances and the effect of the leakage current on the PN junction, which depends on the fabrication method of the PV cell [23].
TABLE 1: KS-10 specifications.

\begin{tabular}{lcc}
\hline Symbol & Parameter & Value \\
\hline$P_{\mathrm{MPP}}$ & Maximum power & $10 \mathrm{~W}$ \\
$V_{\mathrm{MPP}}$ & Maximum power voltage & $16.9 \mathrm{~V}$ \\
$I_{\mathrm{MPP}}$ & Maximum power current & $0.60 \mathrm{~A}$ \\
$V_{\mathrm{OV}}$ & Open-circuit voltage & $21.5 \mathrm{~V}$ \\
$I_{\mathrm{SC}}$ & Short-circuit current & $0.62 \mathrm{~A}$ \\
$R_{s}$ & Series resistance & $1.72 \Omega$ \\
$R_{p}$ & Shunt resistance & $28 \mathrm{k} \Omega$ \\
$\alpha$ & Temperature & $0.27 \mathrm{~mA} /{ }^{\circ} \mathrm{C}$ \\
$\beta$ & coefficient of $I_{\mathrm{SC}}$ & \\
& Temperature & $-82.40 \mathrm{mV} /{ }^{\circ} \mathrm{C}$ \\
\hline
\end{tabular}

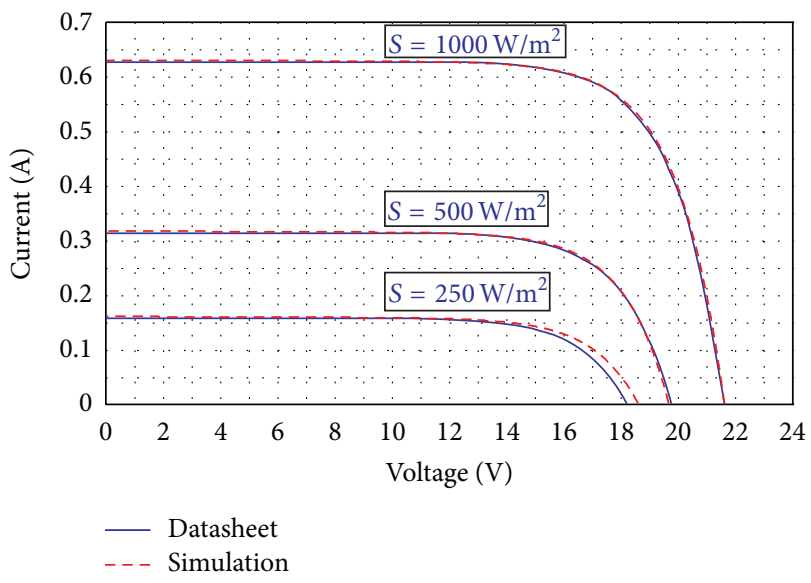

FiguRE 4: $I \times V$ curve for different values of solar irradiance.

Modeling the output current $I$ in the circuit of Figure 3 results in

$$
I=I_{\mathrm{ph}}-I_{D} \cdot\left(e^{q\left(\left(V+I \cdot R_{s}\right) /(\eta \cdot K \cdot T)\right)}-1\right)-\frac{V+I \cdot R_{S}}{R_{P}},
$$

where $V$ is the PV module voltage, $T$ is the measured temperature, $q$ is the electron charge $\left(1,6 \times 10^{-19} \mathrm{C}\right), \eta$ is the $\mathrm{PN}$ junction ideality factor, and $k$ is the Boltzmann constant $\left(1,38 \times 10^{-23} \mathrm{~J} / \mathrm{K}\right)$.

In order to analyze the PV module behavior, (6) was modeled in MATLAB/Simulink and its parameters were adjusted to the Kyocera KS-10 module, presented in Table 1.

The current versus voltage curves, comparing the datasheet points and the simulated data, are shown in Figures 4 and 5. It is possible to observe from these figures that the simulation results are very similar to those presented in the PV module datasheet [24]. These curves are close to the datasheet points, particularly when there is no temperature variation. 


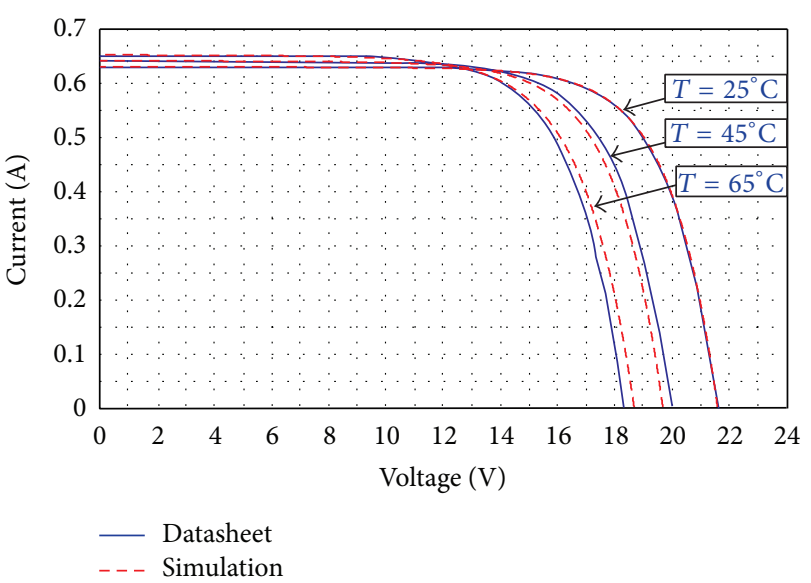

FiguRE 5: $I \times V$ curve for different values of temperature.

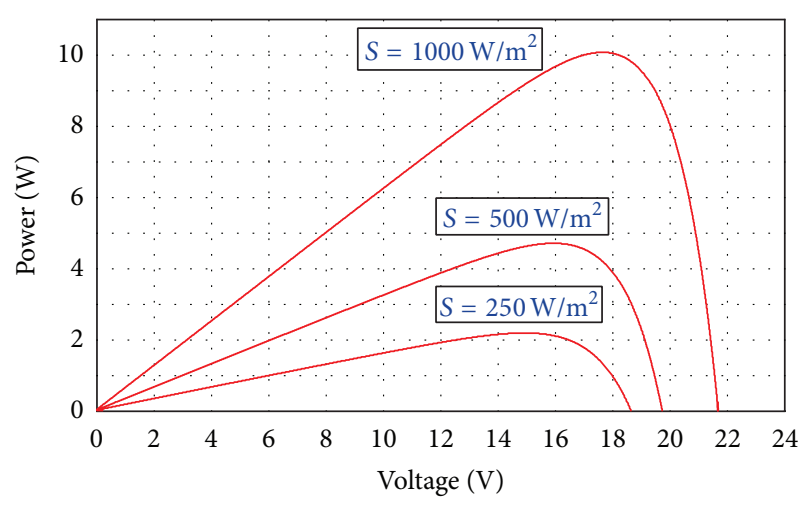

FIgURE 6: $P \times V$ curve for different values of solar irradiance.

Since the photogenerated current is a function of temperature and irradiance, (6) can be rewritten as

$$
\begin{aligned}
I= & \left\{\left[I_{\mathrm{SC}_{\mathrm{ref}}}+\alpha\left(T-T_{\mathrm{ref}}\right)\right] \cdot \frac{S}{S_{\mathrm{ref}}}\right\} \\
& -I_{D} \cdot\left(e^{q\left(\left(V+I \cdot R_{s}\right) /(\eta \cdot K \cdot T)\right)}-1\right)-\frac{V+I \cdot R_{S}}{R_{P}},
\end{aligned}
$$

where $I_{\mathrm{SC}_{\mathrm{ref}}}$ is the reference short-circuit current, $\alpha$ is the sensitivity of current with respect to temperature, $T_{\text {ref }}$ is the temperature under STC $\left(25^{\circ} \mathrm{C}\right), S$ is the measured irradiance, and $S_{\text {ref }}$ is the reference irradiance $\left(1000 \mathrm{~W} / \mathrm{m}^{2}\right)$.

Equation (7) models the behavior of the PV module, which is directly influenced by irradiance and temperature. In general, as the irradiance increases the $\mathrm{PV}$ power increases, while increasing temperature results in PV power reduction [11], as can be seen in Figures 6 and 7.

Based on the observed characteristics and equations, the dependence of the aforementioned variables on the MPP can be evaluated. The method developed by Moradi et al. [11] can extract higher power if compared to the other methods. It uses an irradiance sensor to estimate the MPP, which has high cost [21], when compared with a current sensor cost, and prevents its use on systems with a large number of modules.

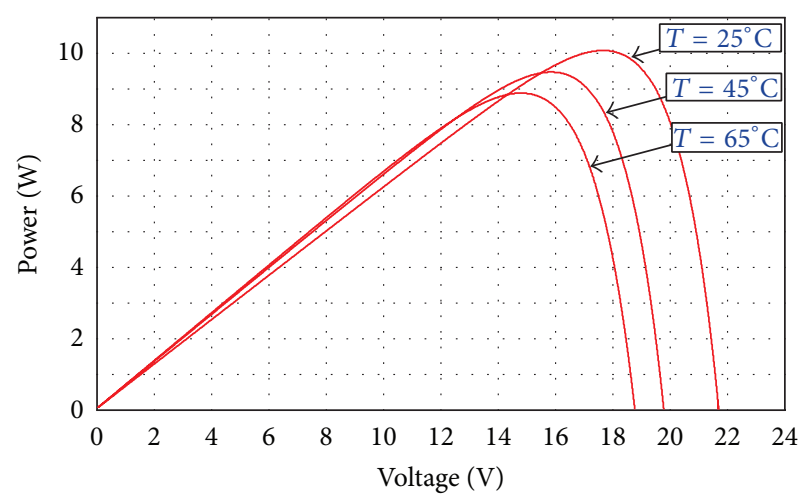

Figure 7: $P \times V$ curve for different values of temperature.

Considering such limitations, a new and simple method to define the MPP is proposed.

\section{Proposed I\&T Method}

This technique is based on the measurement of temperature and the estimation of irradiance through the relationship between the measured short-circuit current $I_{\mathrm{SC}}$ and the reference short-circuit current $I_{\mathrm{SC}_{\text {ref }}}$. The short-circuit current is directly proportional to the irradiance [19].

Besides, the temperature measurement contributes to the increase of the accuracy of the mathematical model. Based on the analysis of (7) and the aforementioned parameters, we can derive the following:

$$
\begin{aligned}
I= & {\left[I_{\mathrm{SC}}+\frac{I_{\mathrm{SC}}}{I_{\mathrm{SC}_{\mathrm{ref}}}} \cdot \alpha\left(T-T_{\mathrm{ref}}\right)\right] } \\
& -I_{D} \cdot\left(e^{q\left(\left(V+I \cdot R_{s}\right) /(\eta \cdot K \cdot T)\right)}-1\right)-\frac{V+I \cdot R_{S}}{R_{P}} .
\end{aligned}
$$

It is necessary to define the output voltage $V$, in order to use (8) as the control system variable. Several approaches to establish this voltage, which directly influences the MPP, were evaluated $[5,7,11,23]$. The open-circuit voltage defined in [5] is the best way of estimating this voltage level. Therefore, (9) can replace (8), which is responsible for estimating the MPP in the proposed method:

$$
\begin{aligned}
I_{\mathrm{MPP}}= & {\left[I_{\mathrm{SC}}+\frac{I_{\mathrm{SC}}}{I_{\mathrm{SC}}} \cdot \alpha\left(T-T_{\mathrm{ref}}\right)\right] } \\
& -I_{D} \cdot\left(e^{\ln \left(I_{\mathrm{ph}} / I_{D}+1\right)+\left(I \cdot R_{s}\right) /(\eta \cdot K \cdot T)}-1\right) \\
& -\frac{\ln \left(I_{\mathrm{ph}} / I_{D}+1\right)((\eta \cdot K \cdot T) / q)+I \cdot R_{S}}{R_{P}} .
\end{aligned}
$$

The control variable of this method is the maximum power point current $I_{\mathrm{MPP}}$, obtained with (9). The output current is measured continuously, and its value is compared with $I_{\mathrm{MPP}}$. 


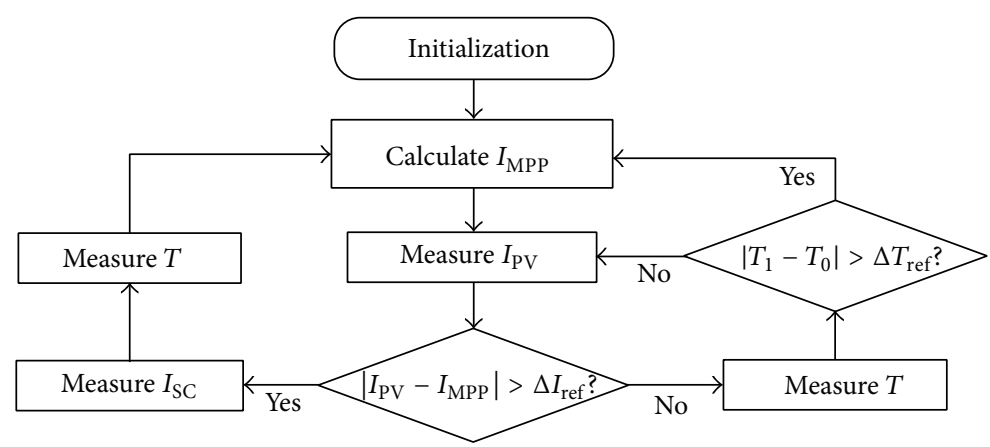

FIGURE 8: Flowchart of the proposed method.

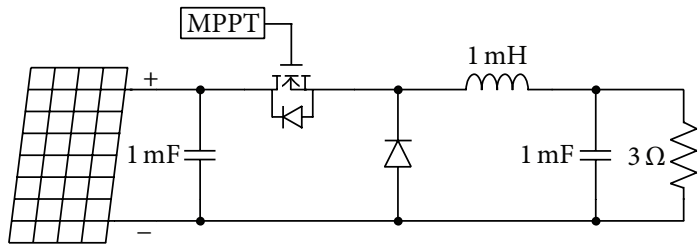

Figure 9: PV system with a buck converter.

\section{Results}

The flowchart of the I\&T method is quite simple and can be seen in Figure 8. Two reference variations have to be defined: temperature variation $\left(\Delta T_{\text {ref }}\right)$ and PV output current variation $\left(\Delta I_{\text {ref }}\right) . \Delta T_{\text {ref }}$ is established to $1^{\circ} \mathrm{C}$, considering that slight variations will not significantly modify the operating point. The same happens with $\Delta I_{\text {ref }}$, which is set at $6 \mathrm{~mA}$, causing the module to disconnect the load to measure $I_{\mathrm{SC}}$ only when the operating conditions have a considerable change.

In the flowchart, after system initialization, $I_{\mathrm{MPP}}$ parameter is defined using (9) and the PV module current $I_{\mathrm{PV}}$ is measured. It is verified if the difference between these currents exceeds the reference variation $\Delta I_{\text {ref }}$. In the affirmative case, which means that a significant change in the operating conditions was made, short-circuit current $I_{\mathrm{SC}}$ and temperature $T$ are measured, and a new value for $I_{\text {MPP }}$ is established. Otherwise, a new temperature value is measured. The difference between the new $T_{1}$ and previous $T_{0}$ temperature values is compared with $\Delta T_{\text {ref. If the difference }}$ is greater than $\Delta T_{\text {ref }}$, a new $I_{\text {MPP }}$ is calculated. On the other hand, the previous value of $I_{\mathrm{MPP}}$ is maintained.

The PV module current $I_{\mathrm{PV}}$ is regularly sampled at $1 \mathrm{kHz}$ frequency $[5,9,11,25]$, to verify any changes in operating conditions and determine whether $I_{\mathrm{SC}}$ is supposed to be measured. It does effectively occur if the operating conditions change significantly. Monitoring $I_{\mathrm{PV}}$ is necessary in order to avoid unnecessary losses [6].

A PV system composed of a single KS-10 module associated with a dc-dc buck converter was simulated in MATLAB/ Simulink. The system and its parameters are presented in Figure 9.

Two sets of tests were carried out to verify the performance of the six MPPT methods, concerning irradiance and temperature variations. For the first test, temperature is kept
Efficiency (\%)

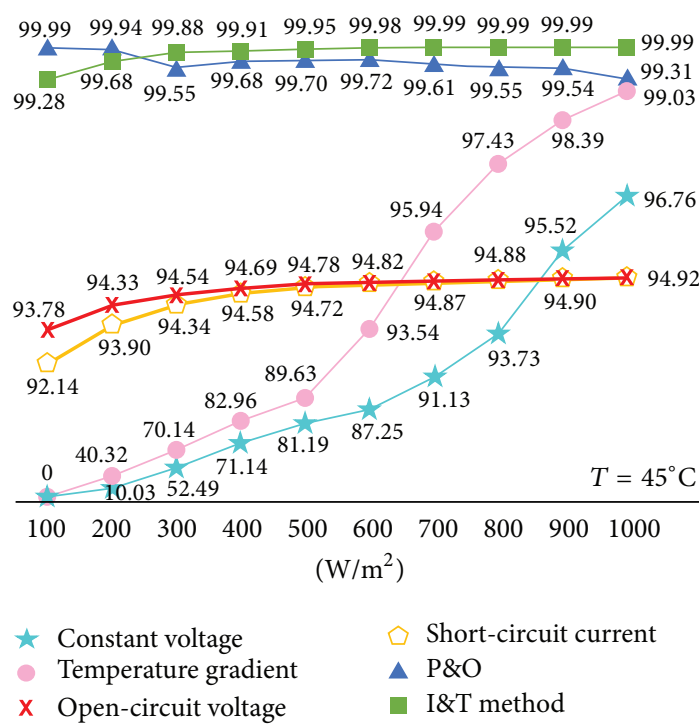

FIGURE 10: Efficiency of MPPT techniques considering irradiance variation.

constant at $45^{\circ} \mathrm{C}$ and irradiance varies from $100 \mathrm{~W} / \mathrm{m}^{2}$ to $1000 \mathrm{~W} / \mathrm{m}^{2}$, in order to evaluate the steady-state behavior of the system [5]. The results are shown in Figure 10.

From Figure 10 it can be seen that the highest efficiency methods are the I\&T, $\mathrm{P} \& \mathrm{O}$, and temperature gradient, respectively. The efficiency values indicate a good approximation of the MPP in steady state.

A closer look in the simulation results of Figure 10, obtained from the six MPPT methods, regarding PV power output with respect to time, in the situation of $1000 \mathrm{~W} / \mathrm{m}^{2}$ and $45^{\circ} \mathrm{C}$, is shown in Figure 11.

In the condition of $1000 \mathrm{~W} / \mathrm{m}^{2}$ and $45^{\circ} \mathrm{C}$ it is possible to observe that the systems with the smaller oscillations around the MPP are, in this order, the I\&T, short-circuit current, and open-circuit voltage. Despite having low oscillation in the MPP, seen in Figure 11, the average efficiency of shortcircuit current and open-circuit voltage methods is below other methods, as shown in Figure 10. This is mainly due to the need for periodic sampling and disconnection of the circuit for parameters measurements. 


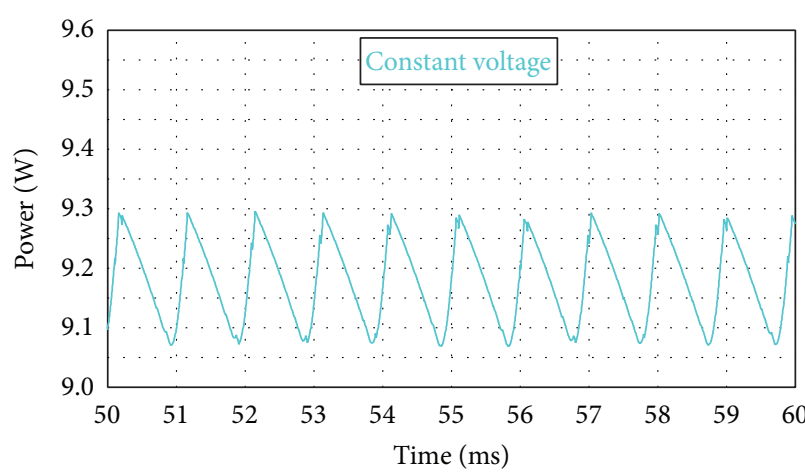

(a)

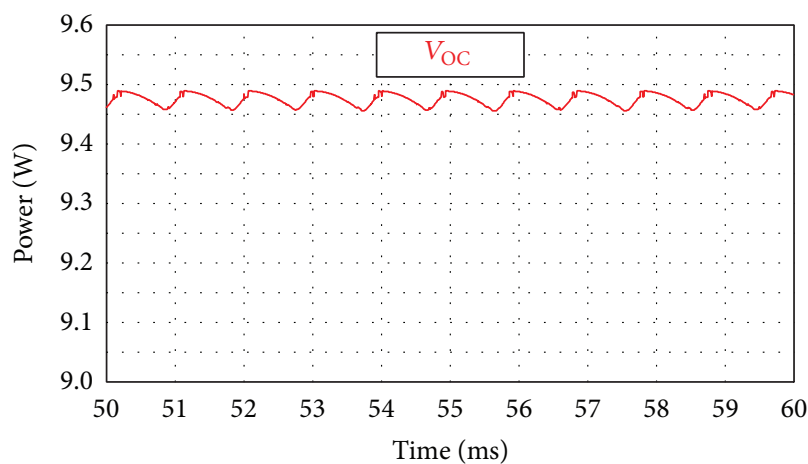

(c)

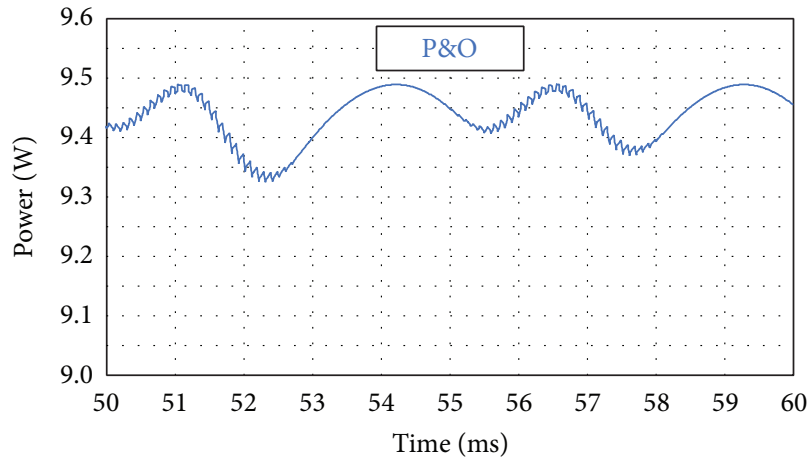

(e)

FIGURE 11: Steady-state behavior of MPPT techniques $\left(1000 \mathrm{~W} / \mathrm{m}^{2}, 45^{\circ} \mathrm{C}\right)$ : (a) constant voltage; (b) temperature gradient; (c) open-circuit voltage; (d) short-circuit current; (e) P\&O; (f) I\&T.

Other four situations have also been evaluated: standard test condition $\left(1000 \mathrm{~W} / \mathrm{m}^{2}, 25^{\circ} \mathrm{C}\right)$; step change in irradiance $\left(1000 \mathrm{~W} / \mathrm{m}^{2}\right.$ to $\left.500 \mathrm{~W} / \mathrm{m}^{2}\right)$; step change in temperature (from $65^{\circ} \mathrm{C}$ to $25^{\circ} \mathrm{C}$ ); and, finally, both step changes in irradiance and temperature. The results are presented in Figure 12.

The proposed method (I\&T) efficiency in Figure 12 is the highest, when compared to other methods, in all situations. It suggests that this method is appropriate to situations of large modifications of irradiance and temperature.

The tracking efficiency is analyzed in Figure 13, for the situation where both step changes in irradiance and temperature occur $\left(1000 \mathrm{~W} / \mathrm{m}^{2}\right.$ to $500 \mathrm{~W} / \mathrm{m}^{2}$ and $65^{\circ} \mathrm{C}$ to $\left.25^{\circ} \mathrm{C}\right)$. The output power of each method is graphically compared with the maximum power (dashed line).

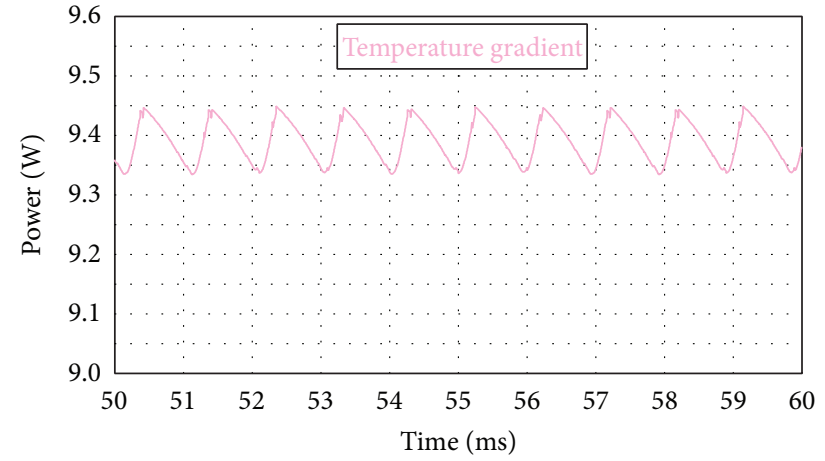

(b)

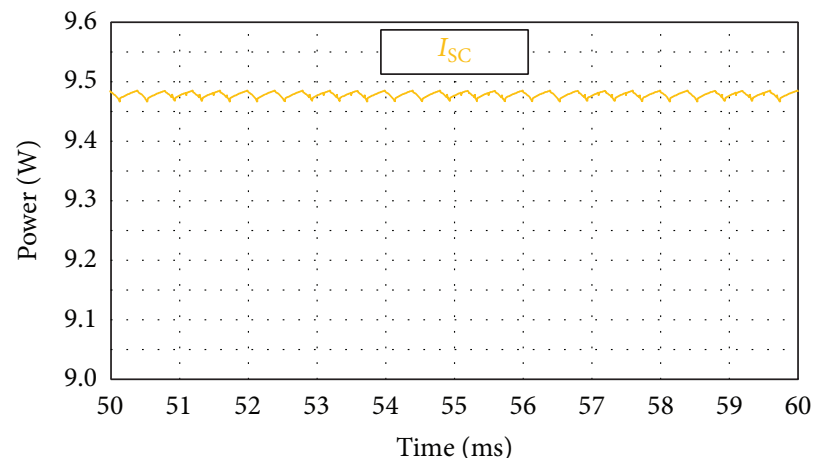

(d)

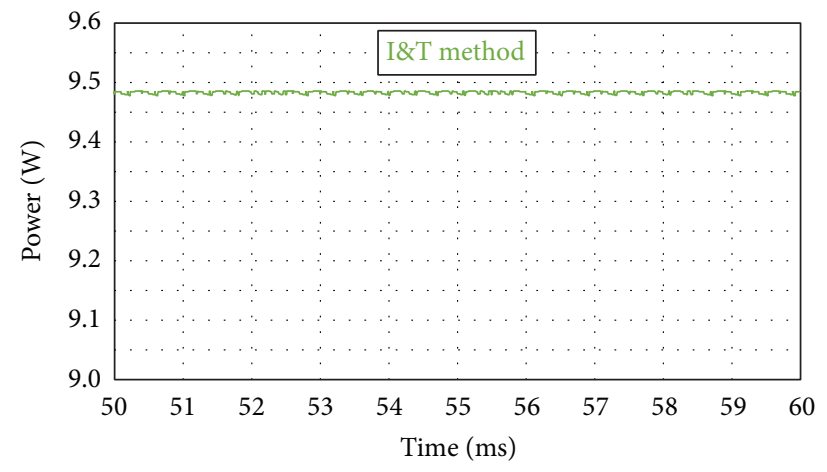

(f)
From results, presented in Figures 10 to 13, it is possible to notice that the use of a reduced number of sensors in methods, such as constant voltage and temperature gradient, has direct impact on the MPPT efficiency, especially at low irradiance levels. The open-circuit voltage and shortcircuit current methods perform periodic sampling of the PV module parameters. These methods present considerable power losses due to the need of disconnecting the circuit for measurement, as well as operating at lower power points between samples $[6,14]$. P\&O method has high efficiency. However, the output power oscillates around the MPP in steady-state condition and the technique is not adequate when there are abrupt variations of solar irradiance [6, 12]. Additionally, it requires greater computational effort 


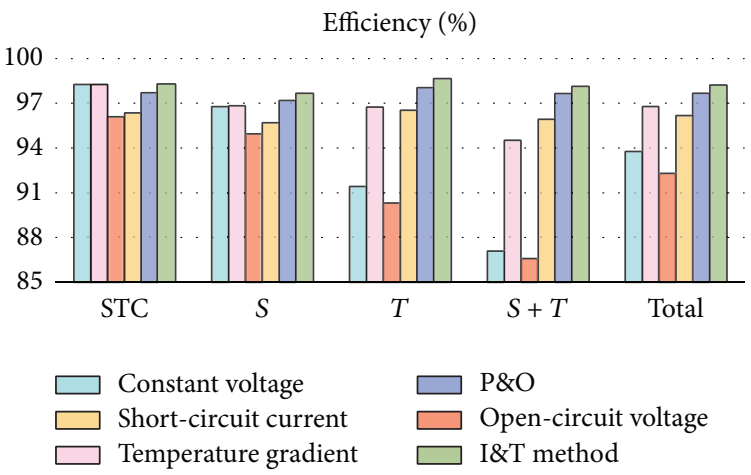

FIGURE 12: Efficiency of MPPT techniques considering both irradiance and temperature variation.

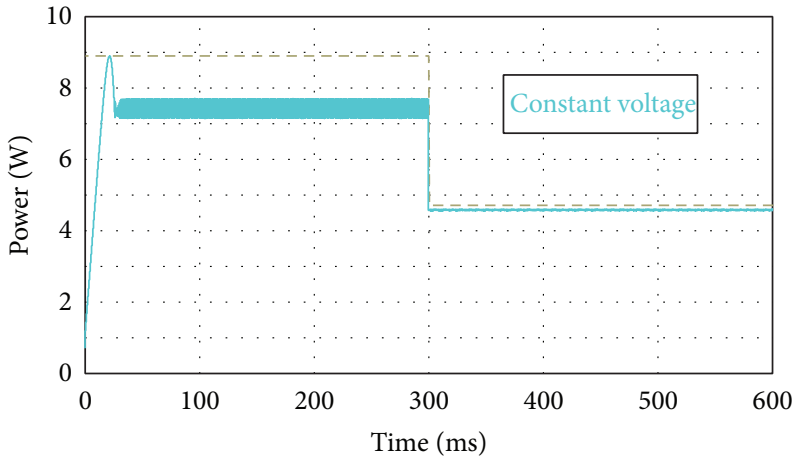

(a)

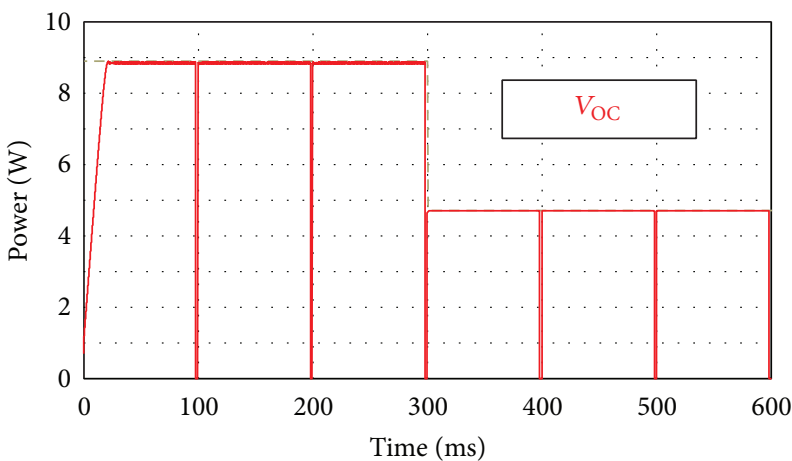

(c)

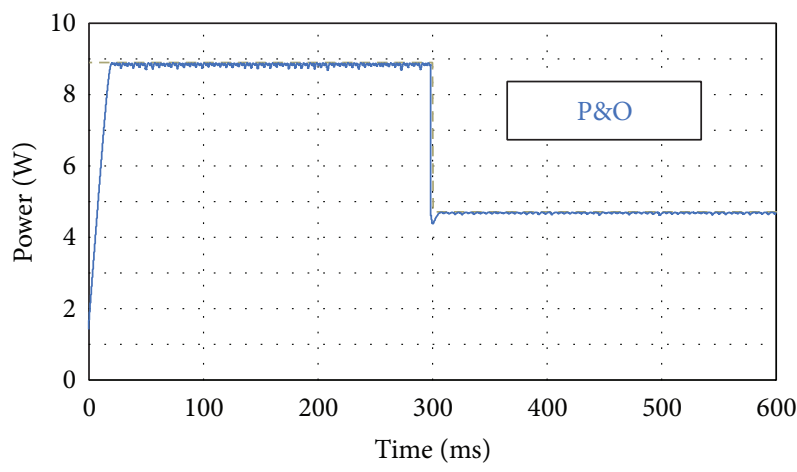

(e)

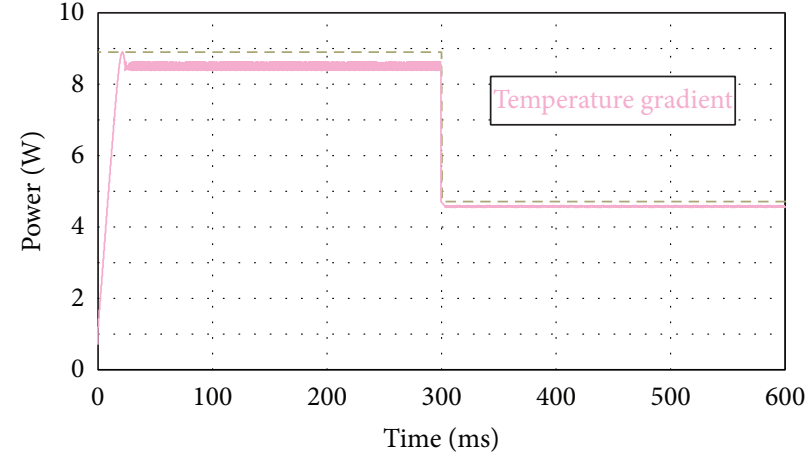

(b)

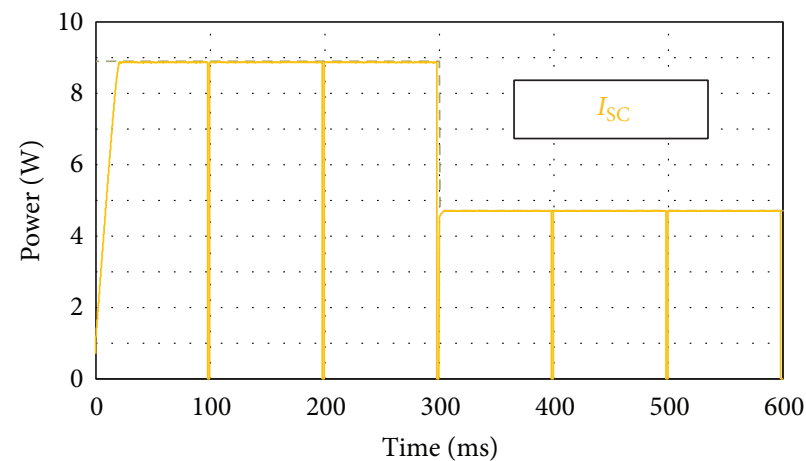

(d)

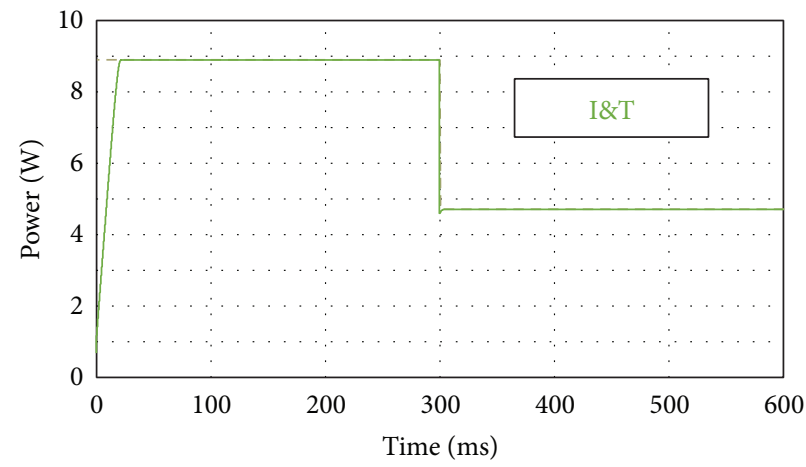

(f)

FIGURE 13: Tracking efficiency of MPPT techniques $\left(1000 \mathrm{~W} / \mathrm{m}^{2}\right.$ to $500 \mathrm{~W} / \mathrm{m}^{2}$ and $65^{\circ} \mathrm{C}$ to $25^{\circ} \mathrm{C}$ ): (a) constant voltage; (b) temperature gradient; (c) open-circuit voltage; (d) short-circuit current; (e) P\&O; (f) I\&T. 
TABLE 2: Efficiency versus irradiation @ $45^{\circ} \mathrm{C}$ (cell temperature), adapted from [5].

\begin{tabular}{lcc}
\hline Irradiation $\left(\mathrm{W} / \mathrm{m}^{2}\right)$ & $\eta$ Christy [5] & $\eta$ I\&T Method \\
\hline 100 & 99.75 & 99.28 \\
200 & 99.90 & 99.68 \\
300 & 99.93 & 99.88 \\
400 & 99.94 & 99.91 \\
500 & 99.94 & 99.95 \\
600 & 99.94 & 99.98 \\
700 & 99.93 & 99.99 \\
800 & 99.92 & 99.99 \\
900 & 99.92 & 99.99 \\
1000 & 99.91 & 99.99 \\
\hline
\end{tabular}

because the extracted power is supposed to be calculated continuously.

The proposed I\&T method has the highest efficiency among all evaluated methods, as seen in Figures 10 to 13, without requiring high computational effort or the use of expensive and complex sensors. Moreover, it presents low ripple in steady-state condition and fast tracking speed, which could be observed in Figure 13.

Furthermore, by comparing the I\&T method results in Figure 10 with the high efficiency TSSE method described by Christy Mano Raj and Ebenezer Jeyakumar [5], the former presents improved performance in $60 \%$ of cases, particularly at high irradiance levels, as can be seen in Table 2 .

\section{Conclusion}

This work has presented a new MPPT technique whose performance is better than other compared methods. The proposed method measures PV temperature and estimates the irradiance through the relationship of the measured short-circuit current and its reference at STC, which is proportional to the irradiance variation and precisely defines the MPP.

Stable steady-state operation and reduced computational efforts are additional features of this approach, which allows it to have lower hardware costs. The I\&T method, according to the simulation results, can extract more than $99.85 \%$ of the available power.

\section{Conflict of Interests}

The authors declare that there is no conflict of interests regarding the publication of this paper.

\section{Acknowledgment}

The authors would like to thank CAPES (Coordination for Improvement of Higher Education Level) for the financial support to this work.

\section{References}

[1] C. L. Archer and M. Z. Jacobson, "Evaluation of global wind power," Journal of Geophysical Research D: Atmospheres, vol. 110, no. 12, pp. 1-20, 2005.

[2] P. Richard and P. Marc, "A fundamental look at energy reserves for the planet," The IEA SHC Solar Update, vol. 50, pp. 2-3, 2009.

[3] A. Goodrich, T. James, and M. Woodhouse, "Residential, commercial, and utility scale photovoltaic (PV) system prices in the United States: current drivers and cost-reduction opportunities," Technical report NREL, Contract 303, 2012.

[4] W. Shockley and H. J. Queisser, "Detailed balance limit of efficiency of p-n junction solar cells," Journal of Applied Physics, vol. 32, no. 3, pp. 510-519, 1961.

[5] J. S. Christy Mano Raj and A. Ebenezer Jeyakumar, "A two stage successive estimation based maximum power point tracking technique for photovoltaic modules," Solar Energy, vol. 103, pp. 43-61, 2014.

[6] R. Faranda and S. Leva, "Energy comparison of MPPT techniques for PV systems," WSEAS Transactions on Power Systems, vol. 3, no. 6, pp. 446-455, 2008.

[7] J. Xu, L. Kang, C. Zhong, and B. Cao, "Photovoltaic power system with MPPT functionality for a small-size electric vehicle," International Journal of Photoenergy, vol. 2014, Article ID 460390, 9 pages, 2014.

[8] B. Subudhi and R. Pradhan, "A comparative study on maximum power point tracking techniques for photovoltaic power systems," IEEE Transactions on Sustainable Energy, vol. 4, no. 1, pp. 89-98, 2013.

[9] H. Rezk and A. M. Eltamaly, "A comprehensive comparison of different MPPT techniques for photovoltaic systems," Solar Energy, vol. 112, pp. 1-11, 2015.

[10] N. Onat, "Recent developments in maximum power point tracking technologies for photovoltaic systems," International Journal of Photoenergy, vol. 2010, Article ID 245316, 11 pages, 2010.

[11] M. H. Moradi, S. M. Reza Tousi, M. Nemati, N. Saadat Basir, and N. Shalavi, "A robust hybrid method for maximum power point tracking in photovoltaic systems," Solar Energy, vol. 94, pp. 266-276, 2013.

[12] O. Wasynczuk, "Dynamic behavior of a class of photovoltaic power systems," IEEE Transactions on Power Apparatus and Systems, vol. 102, no. 9, pp. 3031-3037, 1983.

[13] S. K. Kollimalla and M. K. Mishra, "A Novel Adaptive P\&O MPPT Algorithm Considering Sudden Changes in the Irradiance," IEEE Transactions on Energy Conversion, vol. 29, no. 3, pp. 602-610, 2014.

[14] M. A. S. Masoum and H. Dehbonei, "Design, construction and testing of a voltage-based maximum power point tracker (VMPPT) for small satellite power supply," in Proceedings of the 13th Annual AIAA/USU Conference, Small Satellite, pp. 1-11, Logan, Utah, USA, 1999.

[15] D. Raveendhra, P. Joshi, and R. K. Verma, "Performance and control system design for FPGA based CVMPPT boost converter for remote SPV water pumping system applications," in Proceedings of the Power and Energy Systems Conference: Towards Sustainable Energy (PESTSE '14), pp. 1-6, March 2014.

[16] M. Park and I.-K. Yu, "A study on the optimal voltage for MPPT obtained by surface temperature of solar cell," in Proceedings of the 30th Annual Conference of IEEE Industrial Electronics Society (IECON '04), pp. 2040-2045, Busan, South Korea, November 2004. 
[17] R. F. Coelho, F. M. Concer, and D. C. Martins, "A MPPT approach based on temperature measurements applied in PV systems," in Proceedings of the IEEE International Conference on Sustainable Energy Technologies (ICSET '10), pp. 1-6, December 2010.

[18] D. Raveendhra, B. Kumar, D. Mishra, and M. Mankotia, "Design of FPGA based open circuit voltage MPPT charge controller for solar PV system," in Proceedings of the IEEE International Conference on Circuit, Power and Computing Technologies (ICCPCT '13), pp. 523-527, March 2013.

[19] S. M. Alghuwainem, "Matching of a dc motor to a photovoltaic generator using a step-up converter with a current-locked loop," IEEE Transactions on Energy Conversion, vol. 9, no. 1, pp. 192198, 1994.

[20] T. Noguchi, S. Togashi, and R. Nakamoto, "Short-current pulsebased maximum-power-point tracking method for multiple photovoltaic-and-converter module system," IEEE Transactions on Industrial Electronics, vol. 49, no. 1, pp. 217-223, 2002.

[21] Kipp \& Zonen Asia Pacific, "Lite2 Pyranometer datasheet," http://www.kippzonen.com.

[22] H. J. Möller, Semiconductors for Solar Cells, Artech House, Norwood, Mass, USA, 1993.

[23] M. G. Villalva, J. R. Gazoli, and E. R. Filho, "Comprehensive approach to modeling and simulation of photovoltaic arrays," IEEE Transactions on Power Electronics, vol. 24, no. 5, pp. 11981208, 2009.

[24] Kyocera KS-10 module datasheet, http://www.kyocerasolar .com/assets/001/5210.pdf.

[25] A. M. Latham, R. Pilawa-Podgurski, K. M. Odame, and C. R. Sullivan, "Analysis and optimization of maximum power point tracking algorithms in the presence of noise," IEEE Transactions on Power Electronics, vol. 28, no. 7, pp. 3479-3494, 2013. 

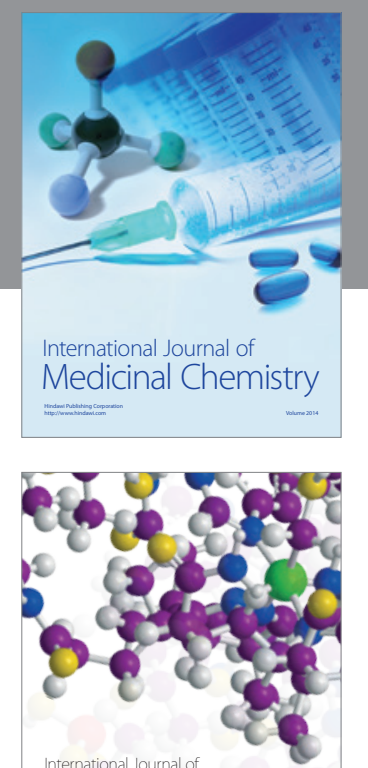

\section{Carbohydrate} Chemistry

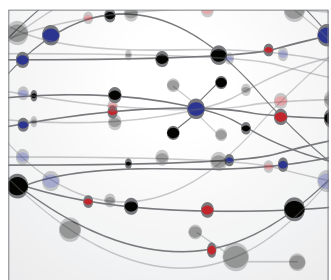

The Scientific World Journal
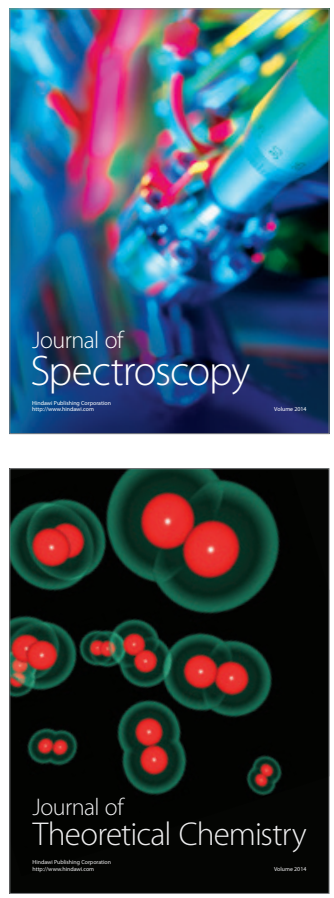
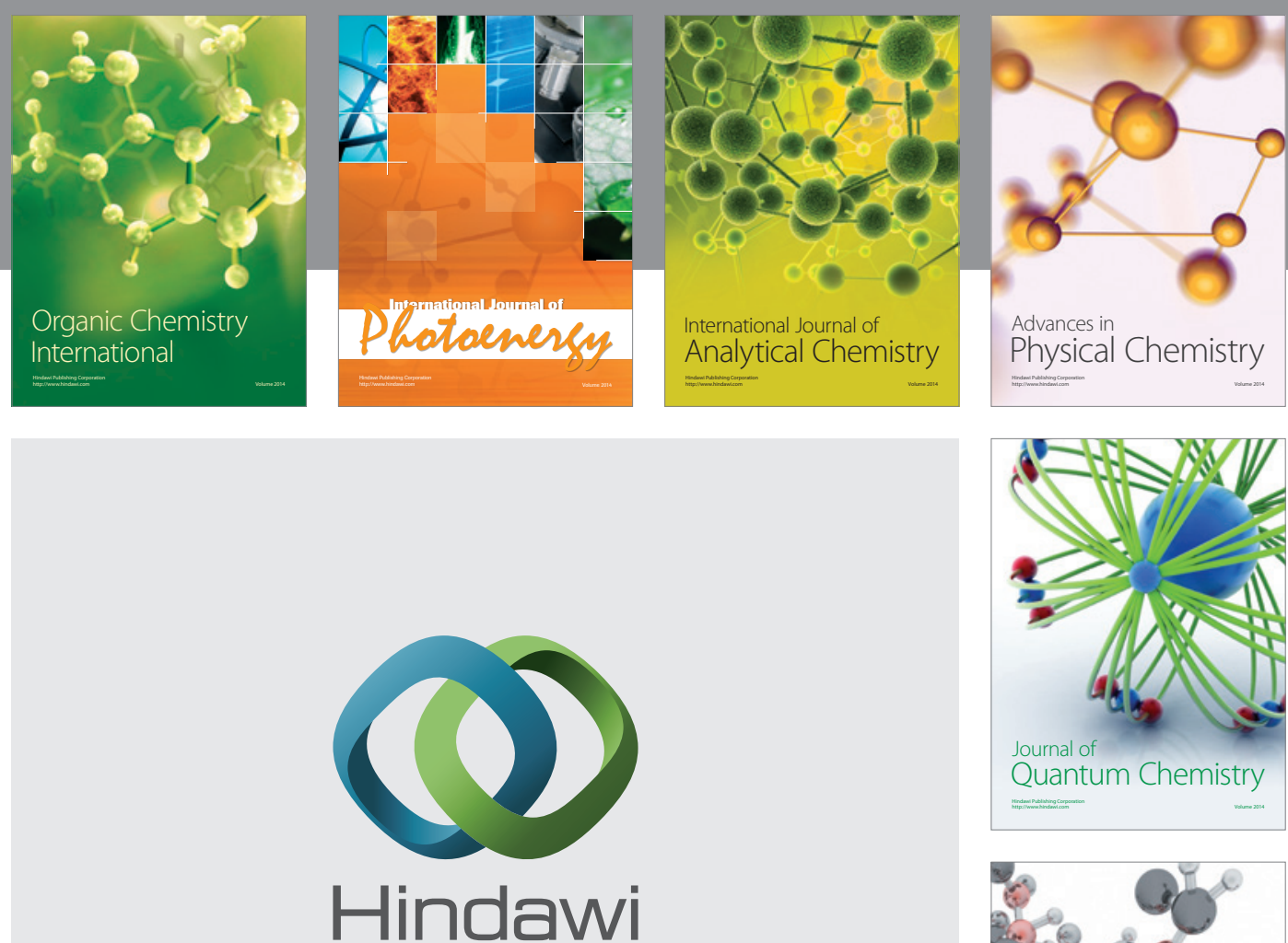

Submit your manuscripts at

http://www.hindawi.com

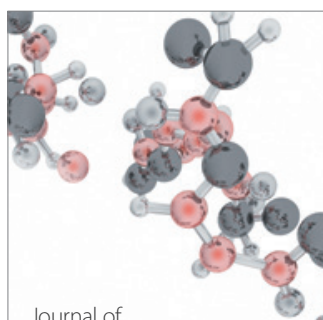

Analytical Methods

in Chemistry

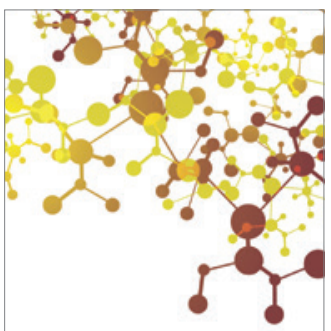

Journal of

Applied Chemistry

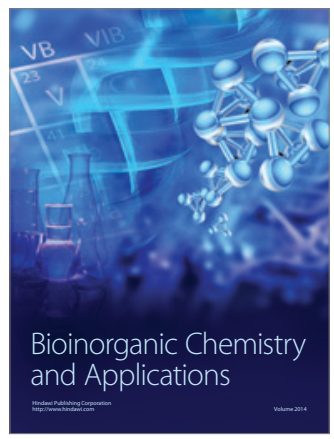

Inorganic Chemistry
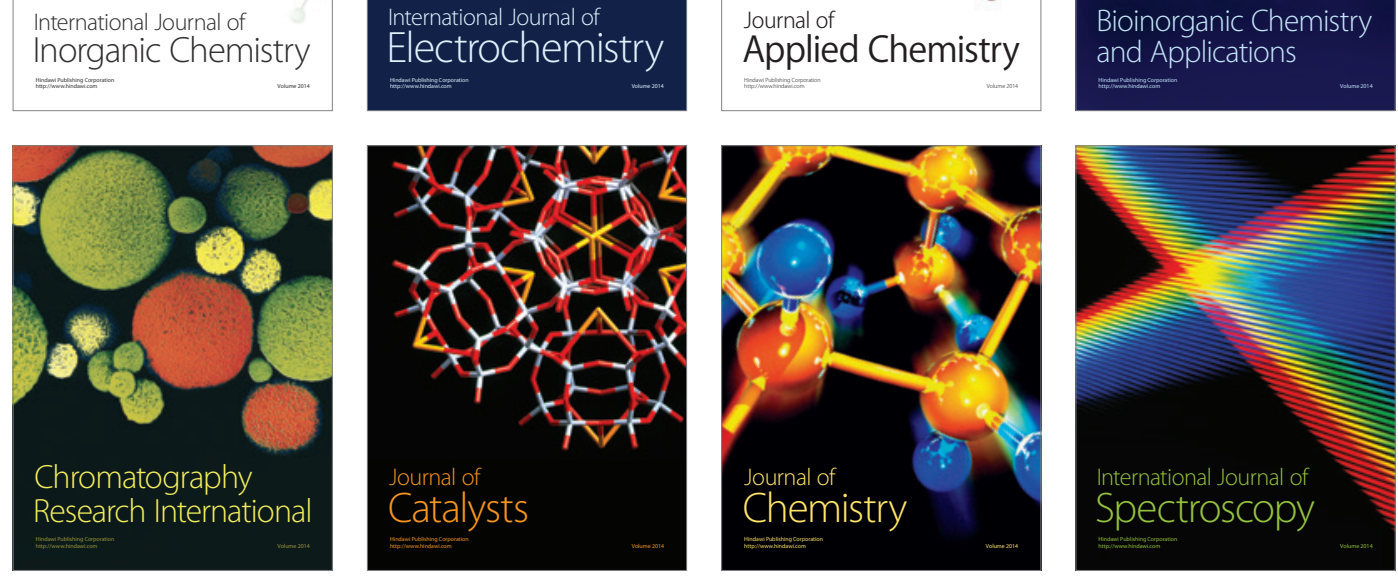